\title{
Don Lindberg's Outreach Legacy at the National Library of Medicine
}

\author{
Elliot R. SIEGEL Ph.D. ${ }^{1}$ \\ U.S. National Library of Medicine (retired)
}

\begin{abstract}
Friends and colleagues of Donald A.B. Lindberg M.D. came together to give tribute to his extraordinary contributions during his tenure (1984-2015) as Director of the U.S. National Library of Medicine (NLM). Dr. Lindberg died in 2019. The book, Transforming biomedical informatics and health information access: Don Lindberg and the U.S. National Library of Medicine. includes four sections. The ten edited chapters in section three (the Outreach section) are briefly summarized in this overview. As Associate Director for Health Information Programs Development, Elliot R. Siegel Ph.D. coordinated NLM's outreach programming under Dr. Lindberg's leadership from its inception in 1989 to his own retirement in 2010. Dr. Lindberg's legacy at NLM is one of new possibilities imagined, significant changes made in the mission and ethos of a venerable institution, and numerous successes achieved in a variety of settings and contexts. Like so much else Dr. Lindberg accomplished, these Outreach programs that profoundly changed the character of NLM would likely not have occurred without him. He made a difference.
\end{abstract}

Keywords. U.S. National Library of Medicine, Donald A.B. Lindberg M.D., Outreach

\section{Introduction}

Friends and colleagues of Donald A.B. Lindberg M.D. came together to give tribute to his extraordinary contributions during his tenure (1984-2015) as Director of the U.S. National Library of Medicine (NLM). Dr. Lindberg died in 2019. The book, Transforming biomedical informatics and health information access: Don Lindberg and the U.S. National Library of Medicine, includes four sections. The ten edited chapters in section three (the Outreach section) are briefly summarized in this overview.

\subsection{Planning for Outreach}

When Dr. Lindberg arrived at NLM in 1984, he brought with him new ideas that motivated staff to pursue with him exciting opportunities for change. Among these was the need for a comprehensive Long Range Plan, the first of its kind for NLM, that was completed in 1987 [1]. A variety of exciting new program possibilities were identified, several of which are discussed in other sections of this book. One emerging possibility, subsequently recognized by Congress encouraged NLM "...to develop an outreach program aimed at... [the] transfer of the latest scientific findings to all health

\footnotetext{
${ }^{1}$ Corresponding author: Elliot R. Siegel, E-mail: siegel.consulting@gmail.com
} 
professionals ..." [2] The mission of NLM was also explicitly amended to add the function to "Publicize the availability of [its] products and services..." [3] This was pursued in greater depth as an update to the Plan, the 1989 DeBakey Report that, in effect, details the origin story of NLM's outreach programs [4].

The Plan's focus was on connecting unaffiliated health professionals in rural and underserved communities to medical libraries. This ultimately grew to an ambitious program of Outreach that was national in scope and intended to serve the diverse information needs of biomedical scientists and research scholars, practicing health professionals, patients, their families, and the public at large.

The chapters in this section report on the influence and impact Dr. Lindberg had on Outreach, along with the programmatic and intellectual contributions he made in the conceptualization of a project and/or its implementation, sometimes with his own considerable personal involvement. The chapters do so through the words and personally recounted stories as told by colleagues and friends who worked with him, and whose own significant contributions are also detailed therein.

\section{Consumer Health Outreach}

When the Internet made possible access to NLM's online information resources without a telecommunications cost to the Library, NLM's institutional outreach commitment was significantly expanded to include 'consumers' -patients, families, and the public. The chapter by Kathleen Cravedi M.S. on Consumer Health Information details several 'revolutions,' including a whirlwind of activity in the 1990s she helped orchestrate as head of NLM's Office of Communications and Public Liaison [5]. Free MEDLINE (the literature citation and abstracts database) had its beginning with the ceremonial launch of Internet Grateful Med by Michael DeBakey M.D. and Sen. Bill Frist in June 1996 at a Friends of the NLM conference. It was followed in April 1997 with a bipartisan congressional press briefing sponsored by Sen. Tom Harkin and Sen. Arlen Specter.

Two months later, it culminated with Vice President Al Gore conducting the first free Internet search of MEDLINE using the new PubMed search system, under the watchful eyes of Dr. Lindberg and NIH Director, Harold Varmus M.D. This was an era in which influential lawmakers on both sides of the aisle unabashedly championed the role of government in protecting the health of the nation's citizens. It also provided political cover enabling NLM to greatly expand the reach of its premier information services without the cost of searching being a barrier to good health. One year later, in 1998, NLM launched the MedlinePlus database and portal whose contents were especially written in plain language, in both English and Spanish. NLM was now firmly in the service of advancing consumer health for everyone.

\section{Outreach for Underserved and Minority Populations}

With these new capabilities came a special commitment by Dr. Lindberg and his outreach team to enhance the capacity of underserved and minority populations to make use of NLM's health information resources on an individual level, and in support of the societal goal of reducing health disparities amongst Black, Hispanic, and Native American populations. 


\subsection{Environmental Health Outreach}

The environmental justice movement had its roots in the 1980's protests against the placement of toxic waste dumps within communities of color that had limited political influence or economic clout. Dr. Lindberg and his outreach team supported that fight with the establishment in 1991 of the Environmental Health Information Partnership (EnHIP) that played to NLM's strength of harnessing the power of health information to help mitigate the risks posed by unsafe exposures to toxic substances. The chapter by Gale A. Dutcher M.S. M.L.S. and John C Scott M.A., presents the story of unique partnerships that began with leading faculty at Historically Black Colleges and Universities (HBCUs) and, over the years, expanded by Dr. Lindborg to include institutions serving Hispanic and Native American communities [6]. The capacitybuilding model they developed deployed computer equipment and telecommunications purchases, along with user training. It would become NLM's longest running outreach program.

\subsection{HIV/AIDS Outreach}

At no time in the early 1990's was the need greater for trustworthy and authoritative information than amongst gay men and communities of color struggling with the deadly HIV/AIDS epidemic. Science was turning the corner on reversing an AIDS diagnosis as a likely death sentence, but much more remained to be done in the laboratory and in the community. Gale Dutcher's chapter on HIV/AIDS traces the beginnings of NLM's second longest-running outreach program, spawned from a landmark NIH conference in 1993 during which the activist public was given a very large microphone and whose appeal for freely accessible life-saving information was dramatically made [7]. Dr. Lindberg heard the message and immediately mandated cost-free searching of NLM's HIV/AIDS databases, an action that anticipated by several years free MEDLINE. But those who would benefit most at the grassroots level often had limited awareness and technical capability to take advantage of the offering. An AIDS community-based information outreach program (ACIOP) was quickly created and launched. It has since funded more than 300 projects reaching thousands of people over the span of decades, evolving with changing needs and opportunities. NLM supported the acquisition of computer equipment, Internet services, user training, and the creation of locally themed and targeted outreach initiatives built atop NLM's national information resources and services

\subsection{Mentoring Urban Youth}

Institutional capacity building is important of course, but it probably places second best to the development of people beginning at a young age. It took the audacious vision of three emergency department physicians in New York City in 2006 to imagine a Mentoring in Medicine (MIM) program geared to urban youth who have a dream to become healthcare professionals. The chapter by Lynne Holden M.D. shows how it was done through live and virtual programs, in school and after-school, utilizing age-specific learning materials, along with culturally themed and engaging exercises [8]. Dr. Lindberg was thoroughly hooked, and he backed MIM with financial support, and he gave of his energy and that of Mary Lindberg who both enthusiastically committed 
themselves to an activity they thoroughly enjoyed, and which gave them great personal pleasure.

\section{Outreach Evaluation}

It is generally accepted in the evaluation community that people do not like themselves or their work to be evaluated by others. At NLM there was also the perception that its online users must be protected from intrusive questions and questioners. Earning trust is therefore critical, and setting conditions where privacy is respected, participation is voluntary, and the benefits of evaluation are achieved with no user complaint, all go a long way towards overcoming these concerns. Important lessons learned and supported by a new Library-wide ethos championed by Dr. Lindberg who was a strong proponent of evaluation from his earliest days at NLM.

\subsection{Are We Making a Difference?}

A pointed question asked by Dr. Lindberg one morning at a senior staff meeting. He wanted to know if we are asking ourselves how effective are NLM's products and services? Are we reaching the people who should be our users? Are we meeting their needs? What are the benefits and outcomes? How might our products and services be changed and improved in response?

He was thinking specifically of NLM's premier offering, MEDLINE, which would soon be subjected to a major first-time evaluation under his guidance using the Critical Incident Technique. The question would also be asked of our outreach programs as well: are we making a difference? The chapter by Frederick B. Wood M.B.A., D.B.A. and Elliot R. Siegel Ph.D. addresses two Lindberg mandates - the need for a robust evaluation capability NLM-wide, and a well-funded outreach program that not only reaches for the low-hanging fruit but is also willing to experiment with novel approaches having moderately high risk and the prospect of significant reward [9]. Two defining evaluation contributions were developed during Dr. Lindborg's tenure.

\subsubsection{Guide to Planning and Evaluating Health Information Outreach}

NLM commissioned the publication of an outreach evaluation Guide intended to fill the knowledge gap of outreach programmers within NLM and collaborators in the field who typically had little or no formal program evaluation experience. A complementary evaluation consultancy also was established to support outreach projects undertaken in the field. Examples discussed in depth in the chapter are outreach projects with Native American tribes in the Northwest (Tribal Connections) and Hispanic communities in the Lower Rio Grande Valley of Texas. All these initiatives were jointly conceived and evaluated in partnership with the National Network of Libraries of Medicine (NN/LM) which is described in a companion chapter in the Outreach section of this book (see section 5).

\subsubsection{Internet/Web Evaluation}

Not to be content solely with user satisfaction surveys and usability testing, NLM undertook a multidimensional approach to evaluation under Dr. Wood's leadership. The 
full range of methodologies is described in the chapter. Among them, NLM experimented with and developed new tools to evaluate the performance of the Internet: end-to-end performance testing. If we are migrating users (domestic and foreign) to the Internet, Dr. Lindberg was rightly concerned this increasingly important means of accessing NLM's products and services, especially by communities already known to have uneven access to the Internet, should function at a level sufficient for their needs. Identifying communications bottlenecks became an obligation and a part of NLM's outreach mission. An interesting test case was pursued following criticism by some foreign users in the Internet's early days, that Americans unfairly consumed all the bandwidth thus making access to NLM's services difficult. But testing clearly showed Americans were asleep when businesses at the other end were responsible for the slow service. Fix your local connections was the advice Dr. Lindberg offered.

\section{A Field Force for Outreach}

NLM is fortunate to have a strong and committed outreach partner in the embodied of the 8000-member National Network of Libraries of Medicine (NN/LM), now the Network of the NLM, as it includes a large contingent of public libraries. As a force for outreach initially identified in the 1989 DeBakey Report, NLM's Library Network has a stellar past going back decades, helping NLM support a myriad of tasks and functions (collection sharing consortia, interlibrary loans, etc.) that could not be fulfilled efficiently alone by the NLM mothership in distant Bethesda, MD. The same concept held true in the more recent past for outreach and evaluation.

The chapter by Jean P. Shipman M.S.L.S., Catherine M. Burroughs M.L.S., and Neil Rambo M.L. describes a variety of outreach functions carried out by the NN/LM in collaboration with NLM [10]. These include many locally initiated outreach projects, as well as those conceived by NLM staff but needing local partners to implement and evaluate them successfully. The Outreach Evaluation Resource Center (the evaluation consultancy noted previously), is a service provided by the NN/LM, and Measuring the Difference: Guide to Planning and Evaluating Health Information Outreach was jointly conceived and executed with the health sciences library at the University of Washington. Dr. Lindberg recognized the unique and critical roles played by the NN/LM, as did those of us in NLM's Office of Health Information Programs Development who relied heavily on its member libraries as advisors, partners, and local ambassadors who facilitated access to the local communities they served.

\section{International Partners and Outreach}

Beginning in 1966, NLM established quid pro quo collaborations with international medical libraries and information centers around the world to provide local access to the MEDLINE database in the form of leased magnetic tape technology. In return, NLM received revenue from searches performed by the International MEDLARS Centers, and assistance with indexing foreign language publications for MEDLINE. These mutually beneficial arrangements numbered 17 in 1987 and reached 20 in 1997, including the Israel MEDLARS Center, which opened in 1994 and operated solely as a local Internet 
resource center providing direct access to NLM's online information resources. Intended by Dr. Lindborg as an innovation in direct and low-cost user access to NLM, it proved instead to be the harbinger of disruptive technology. With the advent of free Medline in 1997 and the ubiquity of Web-based searching, the need for locally provided access to MEDLINE services greatly diminished, and we witnessed the effects that rendered the IMCs largely obsolete.

\subsection{BITNIS}

Even in the heyday of the International MEDLARS Centers, accessing NLM's information resources by users in developing countries was generally prohibitively expensive and impractical, often as difficult as accessing it directly from NLM. An imaginative telecommunications innovation pieced together by a Chilian research scientist, and a computer scientist offered a practical workaround (store-and-forward email searches) that utilized a locally available NASA satellite link to establish a gateway system that interconnected BITNET and NLM's main database server. In his chapter, Victor Cid M.S. (the computer scientist) traces the development of BITNIS (BITNET to NLM Intercommunication System) from its initial launch in 1988, to its maturity from an experimental to a production system serving users in 56 countries throughout Latin America and the newly independent states of the former Soviet Union [11]. As with the MEDLARS Centers, the availability of MEDLINE services free of charge from NLM on a more widespread globally accessible Internet led to the sunsetting of BITNIS. The concept had appealed greatly to Dr. Lindberg who was intrigued by the imaginative use by Mr. Cid of computer and information technology, along with his knitting together a highly unusual network of domestic and international institutional collaborators that literally 'bridged the information gap before the Web'.

\subsection{Multilateral Initiative on Malaria (MIM)}

Malaria research scientists working in Sub-Saharan Africa experienced similar communications difficulties, but these persisted in 1997 and beyond as access to the Internet itself was frequently impossible due to hostile terrain and the physical absence of broadband communications infrastructure in remote areas where the research laboratories generally were located. NIH Director Harold Varmus M.D. and Anthony Fauci M.D., the renowned infectious disease scientist whose Institute was supporting malaria research in Mali, approached Dr. Lindberg for help, knowing of NLM's recent successes with Tribal Connections on Indian reservation. It was seen as an opportunity to make a difference, and Dr. Lindberg accepted the challenge and tasked Dr. Siegel with managing the effort on behalf of NLM. Subsequently, NIH and NLM assumed responsibility for a new communications initiative within the overall Multilateral Initiative on Malaria (MIM) framework. whose goals were to coordinate and enhance malaria research funding and aid capacity-building building efforts in malaria-ravaged Africa. Enhanced and reliable communications capacity was clearly needed to support isolated African scientists' interpersonal communications via email, proposal writing, and literature searching. Dr. Varmus subsequently learned during a briefing by Dr. Siegel that communications connectivity to the journal literature might be insufficient to enable access by the African scientists if the articles were hidden behind an unaffordable publisher-imposed paywall. This motivated Dr. Varmus to become actively engaged in 
the Open Access movement that led to the establishment by NIH/NLM of the PubMed Central repository of full-text journal articles.

\subsubsection{Multilateral Initiative on Malaria Communications Network (MIMCom)}

The chapter by Julia Royall M.A., describes her body of work in Africa, which was enthusiastically supported by Dr. Lindberg [12]. Ms. Royall brought to NLM prior experience in satellite communications, and a strong interest in Africa. MIMCom, and the satellite communications technology (VSAT) she used proved very effective in enhancing or introducing Internet connectivity to medical literature and other online information resources at 27 malaria research sites in 14 African countries. The strategy was shared bandwidth across sites, thus optimizing cost efficiency and effectiveness at each. Pay for what you use, while the underlying networking technology would be in place and scalable. It was a step-by-step building process, demonstrating success at initial sites that engendered confidence, trust, and adoption at new sites down the line. Success was achieved and, at least on the communications side, this enabled a sustainable capacity for research funders and partners alike at each site. Ms. Royall also discusses her efforts to document the impact the new technology had on African scientists, reported in their own words, and very much in the spirit of answering the question, are we making a difference?

\section{Native Voices Exhibition}

Two very important chapters make up the end of the Outreach section. They are special as a tribute to the vision and compassion of Don Lindberg whose interest in Native Americans began as a young third-year medical student doing an in Phoenix, AZ that also took him to the local Indian Health Service Hospital. He never forgot that experience, which generated a latent desire to eventually do something to help the Native American community. This desire was reinforced by his continually growing awareness of health disparities in Indian Country.

The first chapter by Frederick B. Wood M.B.A., D.B.A., Anne R. Altemus M.A., and Elliot R. Siegel Ph.D., tells the story of how that commitment was realized through a years-long scholarly and humanistic program of outreach to Native Americans, and culminating in a unique exhibition that benefitted from the unrivaled story telling capability that is a strength of NLM's History of Medicine's exhibition program [13]. Born of the initial Listening Circles and numerous trust-building visitations that spanned nearly a decade in the making, the Native Voices Exhibition: Stories of Health, Wellness, and Illness from American Indians, Alaska Natives and Native Hawaiians opened in 2011, along with traveling iterations throughout the decade. The exhibition features engaging videographed stories as told to Dr. Lindberg in revealing personal interviews with hundreds of Native elders and healers he interviewed in Alaska, Hawaii and the Lower 48. They recounted the epidemics, cruel government policies, and the inhibition of Native culture of the past, as contrasted with contemporary stories of renaissance, recovery, and self-determination.

At its core, it is a unique cultural asset of recorded history and a living testament to the inspired work of Native elders and healers who gave of their time and selves. Special kudos to Dr. Wood who, from the start, was a serious student of Native healing practices and served as a valuable internal resource to the outreach team as it navigated these new 
learning experiences. The authentic beauty of the exhibition interviews would not have been possible without the inspired, professional videography and technically creative contributions of NLM's audiovisual team, led by Anne Altemus and John Harrington. They connected Dr. Lindberg's passion for photography with his encouragement to shoot b-roll when not recording interviews. "Chase the clouds, and get some good stuff!" he said, as they prepared for a drive toward Denali in Alaska. I will never forget John chasing the setting sun as it illuminated the shadowed tombstones of the historic Kalaupapa cemetery in Hawaii.

\subsection{Reflections}

The second chapter by Katherine Gottlieb D.P.S., M.B.A, Cynthia Lindquist Ph.D., Theodore A. Mala M.D., M.P.H. and Marjorie Mau M.D., M.S. contains personal reflections on Dr. Lindberg and the Native Voices exhibition as told by four amazing Native American leaders and friends [14]. They were instrumental in the successful development of the exhibition, providing invaluable guidance, insight and history to Dr. Lindberg and the outreach team.

Significantly, they enabled trusted access to the Native elders and healers who told their stories to Dr. Lindberg for this unique exhibition and for posterity. As health experts and educators, they share a collective experience bringing together Western Medicine at the intersection with the traditional healing and wellness cultures of Alaska, Hawaii, and Indian Country. NLM's outreach to Native Americans benefitted immensely from their friendship and contributions, and from colleagues in their communities.

\section{Conclusion}

It is very clear NLM would be a far different place had Don Lindberg not been its director. To be sure the needs and interests of research scientists and scholars, and health care providers of various stripes would have continued to be well served, as well as health sciences librarians in their traditional roles. As the chapters in the first two sections of this book attest, Dr. Lindberg's interests and initiatives were pursued with intelligence and gusto, and he achieved tremendous success in their outcomes. In the process, he earned the gratitude, respect, and trust of his colleagues with whom he collaborated.

But our 'George Bailey' also saw other unmet needs: isolated healthcare professionals in remote settings; underserved and underrepresented minority healthcare providers and the disadvantaged patients they served; and the public, whose needs are also addressed in the second section of this book. All became beneficiaries of a robust program of outreach that not only sought to bring authoritative and trusted health information to a greatly expanded universe of users, but also to address from NLM's position of strength as a health information provider the inequities and consequences of health disparities. These are the Lindberg stories recounted in the Outreach section.

There were many memorable experiences along the way. One incident in particular stands out. Early in our outreach travels to connect with Native peoples in Hawaii that would ultimately culminate in the Native Voices Exhibition, our local collaborators in Honolulu organized a Listening Circle with Native Hawaiian community leaders and elders. In an oral history interview conducted by Linda Watson for the Medical Library 
Association in 2014, Don Lindberg recounted an experience that those of us present thought might derail our outreach efforts in Hawaii before they began [15].

"I'd been to lots of Indian places, but I've never been to Hawaii or Alaska. And both turned out to be wonderful people, wonderful places. But the first take in Hawaii was very, very negative. They essentially treated us as one more band of whites from the outside here to take advantage of them some way or another."

(Watson: "Because they didn't know you yet and they didn't trust you.") "Yes. Right, they sure didn't. And so, they told me in a big public meeting that they had their secrets. They knew how to cure AIDS, for example, but don't expect them to tell me. So that was a very painful meeting because it was very public, and we had intended to be nice. And so, I ended up standing up and saying, Wait a minute. Let me tell you something. Here's the NLM. Here's the way it works. Please don't tell me any secrets because I don't have any secrets. Anything you tell me is available free forever to anybody. Any secrets you keep. And it did shut down conversation. There was a sort of radio silence. And I could see them thinking, well, this guy is a son of a bitch but at least he's honest. I just left."

Of course, Don went back. Many times. Stories previously untold outside the Native Hawaiian community were told to him, perhaps some of them were formerly secrets. They were told with trust that they would be respected and shared publicly for the benefit of improving non-Native peoples' understanding of their lives and cultures, and their sacred traditions of Native health and wellness. Don had earned their trust.

I had the privilege of coordinating NLM's outreach programming under Don Lindberg's leadership from its inception in 1989 until the time of my own retirement in 2010. The Native American outreach work that led up to the Exhibition affected me greatly, as it did Don. We both came to learn, understand, and appreciate Native Healing during our many visits, especially his countless videographed interviews with Native healers - Kupuna, like the late Aunty Aggie Cope whom we loved. They helped shape his personal vision for what the Exhibition would seek to accomplish, and in the end his Native American friends said he got it right.

\section{References}

[1] National Library of Medicine (US). Board of Regents. Long range plan. Bethesda, Md.: U.S. Department of Health and Human Services. National Institutes of Health, January 1987.

[2] U.S. Congress, Senate, Committee on Appropriations, Department of Labor, Health and Human Services, and Education and Related Agencies Appropriations Bill, 1987.

[3] U.S. Congress, Joint resolution amending the National Library of Medicine Act, Public Law 100-202, section 215, 1987.

[4] National Library of Medicine (U.S.). Board of Regents. Improving health professionals' access to information. [Internet] Bethesda, Md.: U.S Dept. of Health and Human Services, National Institutes of Health, 1989 [cited 2021 July 8]. 28p. Available from: https://collections.nlm.nih.gov/ext/kirtasbse/8912965/PDF/8912965.pdf

[5] Cravedi K. NLM's revolution in consumer health information to improve patient outcomes. In: Humphreys BL, Logan RA, Miller RA, Siegel ER, editors. Transforming biomedical informatics and health information access: Don Lindberg and the U.S. National Library of Medicine. Amsterdam: IOS Press; 2021.

[6] Dutcher GA, Scott, JC. Environmental Health Information Partnership (EnHIP): strengthening the capacity of minority serving institutions. In: Humphreys BL, Logan RA, Miller RA, Siegel ER, editors. Transforming biomedical informatics and health information access: Don Lindberg and the U.S. National Library of Medicine. Amsterdam: IOS Press; 2021.

[7] Dutcher GA. HIV/AIDS Community Information Outreach Program (ACIOP): A landmark NIH conference and an enduring NLM role in meeting the affected community's need for information access. 
In: Humphreys BL, Logan RA, Miller RA, Siegel ER, editors. Transforming biomedical informatics and health information access: Don Lindberg and the U.S. National Library of Medicine. Amsterdam: IOS Press; 2021.

[8] Holden LM. Mentoring in Medicine (MIM): motivating and enabling disadvantaged youth to become the next generation of minority health professionals. In: Humphreys BL, Logan RA, Miller RA, Siegel ER, editors. Transforming biomedical informatics and health information access: Don Lindberg and the U.S. National Library of Medicine. Amsterdam: IOS Press; 2021.

[9] Wood FB, Siegel ER. Are we making a difference? Outreach evaluation in practice. In: Humphreys BL, Logan RA, Miller RA, Siegel ER, editors. Transforming biomedical informatics and health information access: Don Lindberg and the U.S. National Library of Medicine. Amsterdam: IOS Press; 2021.

[10] Shipman JP, Burroughs CM, Rambo, N. NLM's Library Network: a force for outreach. In: Humphreys BL, Logan RA, Miller RA, Siegel ER, editors. Transforming biomedical informatics and health information access: Don Lindberg and the U.S. National Library of Medicine. Amsterdam: IOS Press; 2021.

[11] Cid V. BITNIS - bridging the information gap before the web. In: Humphreys BL, Logan RA, Miller RA, Siegel ER, editors. Transforming biomedical informatics and health information access: Don Lindberg and the U.S. National Library of Medicine. Amsterdam: IOS Press; 2021.

[12] Royall J. When spider webs unite, they can tie up a lion: NLM's work in information technology and health in Africa, 1997-2011. In: Humphreys BL, Logan RA, Miller RA, Siegel ER, editors. Transforming biomedical informatics and health information access: Don Lindberg and the U.S. National Library of Medicine. Amsterdam: IOS Press; 2021.

[13] Wood FB, Altemus AR, Siegel ER. Native Voices Exhibition: stories of health, wellness, and illness from American Indians, Alaska Natives, and Native Hawaiians. In: Humphreys BL, Logan RA, Miller RA, Siegel ER, editors. Transforming biomedical informatics and health information access: Don Lindberg and the U.S. National Library of Medicine.. Amsterdam: IOS Press; 2021.

[14] Gottlieb K, Lindquist C, Mala TA, Mau MKLM. Reflections on Dr. Donald A.B. Lindberg and Native Voices. In: Humphreys BL, Logan RA, Miller RA, Siegel ER, editors. Transforming biomedical informatics and health information access: Don Lindberg and the U.S. National Library of Medicine. Amsterdam: IOS Press; 2021.

[15] Donald A.B. Lindberg, M.D. interview by Linda A. Watson. [Internet] October 31, 2014 [cited 2021 July 9], transcript, MLA Oral Histories. Medical Library Association, Chicago, IL. Available from: https://www.mlanet.org/blog/lindberg-donald-ab-md 